\title{
Prevalence and causes of thrombocytopenia in an academic state sector laboratory in Soweto, Johannesburg, South Africa
}

\author{
J L Vaughan, MB BCh, FCPath (Haem) (SA), MMed (Haem); J Fourie, MB ChB; S Naidoo, MB BCh; N Subramony, MB ChB; \\ T Wiggill, MB BCh, MMed (Haem); N Alli, MB BCh, FCPath (Haem) (SA)
}

Department of Molecular Medicine and Haematology, Faculty of Health Sciences, University of the Witwatersrand, Johannesburg, South Africa, and National Health Laboratory Service, Johannesburg

Corresponding author:J Vaughan (jenifer.vaughan@nhls.ac.za)

\begin{abstract}
Background. Causes of thrombocytopenia range from laboratory errors to life-threatening pathological conditions. To establish the cause, appropriate laboratory investigation is required.

Objectives. To determine the prevalence and causes of platelet counts $<100 \times 10^{9} / \mathrm{L}$ in state health facilities in Johannesburg, South Africa, as well as the quality of the subsequent laboratory work-up in this setting.

Methods. Full blood counts (FBCs) performed on 7 randomly selected days at the National Health Laboratory Service laboratory at Chris Hani Baragwanath Academic Hospital were retrospectively reviewed. Samples with platelet counts $<100 \times 10^{\%} / \mathrm{L}$ were identified, and pertinent information was extracted from the laboratory database.

Results. Of 4456 FBCs included, $381(8.6 \%)$ had a platelet count of $<100 \times 10^{9} / \mathrm{L}$. Thrombocytopenia prevalence rates were high in haematology/oncology wards (34.4\%), intensive care units (20.5\%) and medical wards (18.7\%) and among neonatal inpatients (16.5\%), and were lowest in outpatient clinics $(1-2 \%)$. A cause was apparent in $\sim 60 \%$ of patients, the commonest causes being chemotherapy and sepsis (each comprising $>20 \%$ of the recognised causes). Spurious thrombocytopenia, disseminated tuberculosis, aplastic anaemia, immune thrombocytopenia and malignant marrow infiltration each accounted for $5-10 \%$ of the causes, while malaria, thrombotic thrombocytopenic purpura, HIV effect and liver disease were each identified in $<5 \%$ of cases. HIV status was documented in $\sim 70 \%$ of the patients, of whom $\sim 50 \%$ tested positive. The quality of the laboratory work-up showed differences between specialties within the hospital setting, and was poorest in the primary healthcare clinic sector.

Conclusion. Thrombocytopenia is common in hospitalised patients in the Johannesburg academic state sector. Differences in the quality of the laboratory work-up emphasise the need for a standardised approach to thrombocytopenia investigation and increased awareness among clinicians.
\end{abstract}

S Afr Med J 2015;105(3):215-219. DOI:10.7196/SAMJ.8791

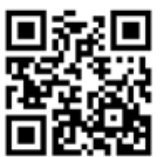

The full blood count (FBC) is among the most frequently requested laboratory tests, and a low platelet count is a common finding. Thrombocytopenia is defined as a platelet count below the normal reference range $\left(\sim 150 \times 10^{9} / \mathrm{L}\right.$ in adults), but is most clinically significant when the platelet count is $<100 \times 10^{9} / \mathrm{L}^{\left[{ }^{[1]}\right.}$ The causes of thrombocytopenia range from laboratory errors to life-threatening medical emergencies, and appropriate laboratory investigation is indicated in its work-up. First-line testing includes a differential white cell count and peripheral blood smear microscopy, which serve as a guide for further investigation. This could include bone marrow aspirate and trephine biopsy examination, exclusion of an underlying coagulopathy, and testing for a variety of infections. ${ }^{[1,2]}$ In the South African (SA) context, exclusion of HIV infection is particularly important, as this may cause thrombocytopenia through several mechanisms. These include involvement of the bone marrow by opportunistic infections and malignancies and increased incidences of immune thrombocytopenia (ITP) and thrombotic thrombocytopenic purpura (TTP), as well as impaired platelet production as a result of both HIV-associated stromal cell dysfunction ${ }^{[3]}$ and direct HIV infection of megakaryocytes. ${ }^{[4]}$ The aims of this study were to determine: $(i)$ the prevalence and causes of platelet counts $<100 \times 10^{9} / \mathrm{L}$ in the state sector in Johannesburg, SA, with emphasis on the effect of HIV infection; and (ii) the adequacy of the subsequent laboratory investigation. For this purpose, FBCs performed at the National Health Laboratory Service laboratory at Chris Hani Baragwanath Academic Hospital (CHBAH) were retrospectively reviewed. This laboratory serves several strata of public health services in Soweto, Johannesburg, ranging from over 50 primary healthcare (PHC) clinics to $\mathrm{CHBAH}$.

\section{Methods}

Sample selection and data collection

FBCs performed on 7 non-consecutive days in 2012 were extracted from the laboratory information system (DisaLab Version 04.16.04.373). Sample selection was random, but in order to avoid temporal bias with respect to the prevalence or causes identified, each day of the week as well as each season of the year were equally represented. Samples with platelet counts $<100 \times 10^{9} / \mathrm{L}$ were identified, and details available in patients' laboratory histories recorded. These included the clinical history, demographic details, evidence of infection (including HIV), presence of a coagulopathy, peripheral blood and bone marrow microscopy findings, and the results of any other investigations judged to be pertinent. The cause for the thrombocytopenia (if apparent) was documented, and the adequacy of the laboratory work-up judged in accordance with previously published recommendations. ${ }^{[1,2]}$ Peripheral blood 
Table 1. Patient epidemiological data, location and TP

\begin{tabular}{|c|c|c|c|c|}
\hline & $\begin{array}{l}\text { Platelet count }>100 \times 10^{\%} / \mathrm{L} \\
(\mathrm{N} 1=4075) \\
n(\%)\end{array}$ & $\begin{array}{l}\text { Platelet count }<100 \times 10^{9} / \mathrm{L} \\
(\mathrm{N} 2=381) \\
n(\%)\end{array}$ & $\begin{array}{l}\text { TP } \\
\mathrm{N} 2 /(\mathrm{N} 1+\mathrm{N} 2)(\%)\end{array}$ & $p$-values \\
\hline Age (years), mean (SD) & $37.6(0.6)^{*}$ & $30.6(2.1)^{\dagger}$ & N/A & $<0.0001$ \\
\hline WCC $\left(\times 10^{9} / \mathrm{L}\right)$, mean $(\mathrm{SD})$ & $8.32(0.18)$ & $9.77(3.5)$ & N/A & 0.019 \\
\hline $\mathrm{Hb}(\mathrm{g} / \mathrm{dL})$, mean $(\mathrm{SD})$ & $11.8(0.1)$ & $9.8(0.3)$ & N/A & $<0.0001$ \\
\hline All patients & - & - & $381 / 4456(8.6)$ & N/A \\
\hline Medical & $479(11.8)$ & $110(28.9)$ & $110 / 589(18.7)$ & $<0.0001$ \\
\hline Surgical & $493(12.1)$ & $26(6.8)$ & $26 / 519(5.0)$ & 0.002 \\
\hline Obstetrics/gynaecology & $252(6.2)$ & $19(5.0)$ & 19/ $271(7.0)$ & 0.35 \\
\hline Haematology/oncology & $168(4.1)$ & $88(23.1)$ & $88 / 256(34.4)$ & $<0.0001$ \\
\hline Paediatrics ${ }^{\ddagger}$ & $186(4.6)$ & $15(3.9)$ & $15 / 201(7.5)$ & 0.28 \\
\hline Neonatal wards & $129(3.2)$ & $23(6.3)$ & $23 / 152(16.5)$ & 0.0005 \\
\hline ICUs & $159(3.9)$ & $41(10.8)$ & $41 / 200(20.5)$ & $<0.0001$ \\
\hline Casualty & $234(5.7)$ & $10(2.6)$ & $10 / 244(4.1)$ & 0.013 \\
\hline Miscellaneous outpatient clinics & $956(23.5)$ & $17(4.4)$ & $17 / 973(1.7)$ & $<0.0001$ \\
\hline PHC clinics & $824(20.2)$ & $12(3.1)$ & $12 / 836(1.4)$ & $<0.0001$ \\
\hline \multicolumn{5}{|c|}{$\begin{array}{l}\text { WCC = white cell count; } \mathrm{Hb}=\text { haemoglobin value; } \mathrm{N} / \mathrm{A}=\text { not applicable. } \\
{ }^{*} N=4006 \text {. } \\
{ }^{*} N=378 \text {. } \\
\text { 'Excluding neonates, paediatric oncology and ICU. } \\
\text { 'Inludes maternity high- care and coronary care units. } \\
\text { 'Statistically significant results are shown in bold. }\end{array}$} \\
\hline
\end{tabular}

smear review was regarded as a minimum essential additional test. Investigations for infection-related causes of thrombocytopenia (such as bacterial sepsis, viral hepatitis, etc.) were similarly regarded as mandatory in cases where a cause was not apparent from either the peripheral smear or the clinical history. In the presence of red cell fragments on the peripheral smear or any clinical risk factors for disseminated intravascular coagulation (DIC) (such as sepsis, trauma, etc.), a coagulopathy screen was considered to be indicated (except in neonates), and if ITP was the favoured cause for the low platelet count, testing for secondary causes (such as an underlying autoimmune pathology or viral infection, particularly viral hepatitis) was judged necessary. The need for further investigation (such as a bone marrow aspirate and trephine biopsy) was judged on a case-by-case basis. Analysis was conducted by medical staff (consultants and registrars) in the Department of Molecular Medicine and Haematology at the University of the Witwatersrand, Johannesburg, and the study was approved by the university's human research ethics committee.

\section{Assessment of work-up adequacy}

The thrombocytopenia work-up was considered adequate if the cause for the thrombocytopenia was discovered and/or all the indicated laboratory investigations were performed. If only some of the investigations were performed, the work-up was judged to be partially adequate, and if no additional laboratory investigation was performed, it was considered inadequate. Although HIV testing is a crucial component of thrombocytopenia investigation in SA, this was excluded from our analysis of work-up adequacy because it was not possible to determine which patients were known to be HIV-positive from previous testing at an alternative site.

\section{Statistical analysis}

Statistical analysis was performed using Statistica software, version 12.0 (StatSoft (Pty) Ltd). Continuous data are presented as means (standard deviation (SD)) and categorical data as frequencies and percentages. Means were compared using Student's $t$-test, and categorical variables using the $\chi^{2}$ statistic or Fisher's exact test when necessary. Multivariate logistic regression was performed to determine predictors of the presence of a coagulopathy. Data were presented as odds ratios (ORs) with 95\% confidence intervals (CIs). Statistical significance was accepted at a two-sided $p$-value of $\leq 0.05$.

\section{Results}

\section{Thrombocytopenia prevalence (TP)}

A total of 4456 FBCs were extracted from the laboratory database, of which $381(8.6 \%)$ had platelet counts $<100 \times 10^{9} / \mathrm{L}$. The registered patient locations included inpatient, outpatient and casualty facilities of CHBAH, as well as PHC clinics in Soweto (Table 1). Thrombocytopenia was most commonly encountered in the haematology/oncology wards/clinic, in the intensive care units (ICUs) and among medical and neonatal inpatients, where the TP rates were $34.4 \%, 20.5 \%, 18.7 \%$ and $16.5 \%$, respectively. Conversely, thrombocytopenia was least frequent in patients seen in nonhaematology/oncology outpatient (TP 1.7\%) and PHC clinic facilities (TP 1.4\%) (Table 1).

\section{Causes of thrombocytopenia identified}

Fifteen of the original samples with thrombocytopenia were found to be repeat specimens collected from the same patient on the same day, and these were excluded from further analysis. For the remaining 366 patients, a cause for the thrombocytopenia was apparent from the laboratory records in 229 (62.6\%), unclear in 95 (26.0\%) and completely unknown in $42(11.5 \%)$. Chemotherapy and sepsis together comprised $>40 \%$ of the causes identified. Spurious thrombocytopenia, disseminated tuberculosis involving the bone marrow (BMTB), aplastic anaemia, ITP and a malignant marrow infiltration each accounted for $5-10 \%$ of the causes, while malaria, TTP, HIV effect and liver disease were each present in $<5 \%$ of cases (Table 2). 
Table 2. Causes of thrombocytopenia identified

\begin{tabular}{|c|c|c|}
\hline & $\begin{array}{l}\text { Total cohort with } \\
\text { a cause identified } \\
(N=229) \\
n(\%)\end{array}$ & $\begin{array}{l}\text { Causes identified in patients with } \\
\text { known HIV status } \\
\text { HIV-positive }(N=83) \text { v. HIV } \\
\text { negative }(N=99), n(\%) ; p \text {-value }\end{array}$ \\
\hline Chemotherapy $^{*}$ & $47(20.5)$ & $\begin{array}{l}15(18.1) \text { v. } 26(26.3) ; \\
0.13\end{array}$ \\
\hline Sepsis & $56(24.5)$ & $\begin{array}{l}21(25.3) \text { v. } 16(16.2) ; \\
0.09\end{array}$ \\
\hline Spurious thrombocytopenia & $13(5.7)$ & $\begin{array}{l}4(4.8) \text { v. } 1(1.0) ; \\
0.13\end{array}$ \\
\hline TTP & $4(1.7)$ & $\begin{array}{l}3(3.6) \text { v. } 1(1.0) \text {; } \\
0.25\end{array}$ \\
\hline Malaria & $7(3.1)$ & $\begin{array}{l}0(0.0) \text { v. } 3(3.0) ; \\
0.16\end{array}$ \\
\hline Malignant marrow infiltrate & $17(7.4)$ & $\begin{array}{l}3(4.8) \text { v. } 14(14.1) \text {; } \\
\mathbf{0 . 0 1 3}\end{array}$ \\
\hline ITP & $19(8.3)$ & $\begin{array}{l}8(9.6) \text { v. } 11(11.1) ; \\
0.5\end{array}$ \\
\hline Aplastic anaemia & $22(9.6)$ & $\begin{array}{l}3(3.6) \text { v. } 19(19.2) \text {; } \\
\mathbf{0 . 0 0 0 9}\end{array}$ \\
\hline ВMTB & $16(7.0)$ & $\begin{array}{l}16(19.3) \text { v. } 0(0.0) \text {; } \\
<0.0001\end{array}$ \\
\hline HIV effect ${ }^{\dagger}$ & $6(2.6)$ & $\begin{array}{l}6(7.2) \text { v. } 0(0.0) \text {; } \\
\mathbf{0 . 0 0 8}\end{array}$ \\
\hline Liver disease & $8(3.5)$ & $\begin{array}{l}2(2.4) \text { v. } 2(2.0) \text {; } \\
0.6\end{array}$ \\
\hline
\end{tabular}

HIV test results were available in 261 (71.3\%) of the patients with a low platelet count, of whom just under half tested positive. BMTB was significantly more prevalent among the HIVpositive patients than among those who were negative (Table 2), while thrombocytopenia due to aplastic anaemia and a malignant marrow infiltrate were seen more often in HIV-negative patients. All patients who had BMTB were HIVpositive, with evidence of AIDS in all those in whom a CD4 count was available.

Hepatitis B and C serology was performed in $84(23.0 \%)$ and $73(20.0 \%)$ of the 366 patients, respectively. Of these, $11 / 84$ (13.1\%) tested positive for hepatitis B surface antigen and $4 / 73$ (5.5\%) for hepatitis C. The cause of the thrombocytopenia was evident in $12 / 15$ (80.0\%) of the patients with either hepatitis B or C; of these, $5 / 12(41.7 \%)$ had evidence of liver disease, $2 / 12(16.7 \%)$ and 2/12 (16.7\%) had BMTB or a malignancy, respectively, and only $1 / 12(8.3 \%)$ had ITP. Of interest was that none of the patients with aplastic anaemia was proven to be either hepatitis B- or C-positive.

\section{Laboratory work-up}

Peripheral blood smear review was performed in 292 patients (79.8\%), and 102
(27.9\%) had had a recent bone marrow aspirate and trephine biopsy. Cultures of a variety of specimen types were performed in 232 patients $(63.4 \%)$, of whom 33 (14.2\%) had documented evidence of bacterial infection. Coagulation testing was requested in 150 patients $(41.0 \%)$ and revealed some evidence of a coagulopathy in $35(23.3 \%)$ of the tested patients. Of note was that coagulation testing was performed in only $48.6 \%$ of patients with documented sepsis (excluding neonatal patients). Multivariate logistic regression revealed significant independent associations between the presence of a coagulopathy and sepsis (OR 4.5 (95\% CI 3.9 - 5.0); $p=0.006$ ), liver disease (OR 34.3 (95\% CI 33.0 - 35.5); $p=0.005$ ) and BMTB (OR 5.3 (CI $4.7-6.0) ; p=0.017$ ).

\section{Adequacy of laboratory work-up}

Laboratory work-up was judged to be adequate in 181 patients (49.5\%), partially adequate in $143(39.1 \%)$ and completely inadequate in $42(11.5 \%)$. Investigation was most complete in neonatal and haematology/ oncology patients, where the work-up was adequate in $>80 \%$ of cases. Completely inadequate work-up very seldom occurred in paediatric and ICU patients $(<1 \%$ and $2.7 \%$, respectively). Work-up was generally suboptimal in surgical inpatients and those seen in non-haematology outpatient clinics, both of which had an inadequate work-up in $>25 \%$ of cases. Work-up was very poor in patients seen in PHC clinics, with $>90 \%$ having a completely inadequate work-up (Table 3). Reasons for work-up inadequacy varied, but important contributors included omission of peripheral blood smear review in 70 patients $(37.8 \%$ of those with an incomplete work-up). This was most striking in patients seen in PHC clinics, where peripheral smear review was performed in only one patient. There was failure to screen for a coagulopathy in 118 (63.7\%) of the 185 patients with an incomplete work-up, with a full DIC screen performed in only eight (4.3\%) of these patients (Table 3). Among the patients with an incomplete work-up, the omission of a coagulopathy screen was relatively more common in medical patients, while testing in ICU, surgical or haematology/oncology patients was generally carried out more frequently.

\section{Discussion}

This study reveals that thrombocytopenia is common among hospitalised patients in the Johannesburg academic state sector, particularly among haematology/oncology patients, neonatal inpatients and patients admitted to medical wards or ICUs. In contrast, a low platelet count is unusual in patients seen in PHC clinics or nonhaematology/oncology outpatient clinics, being present in only $1-2 \%$ of the FBCs received from these locations. However, since $>40 \%$ of the FBCs processed at the $\mathrm{CHBAH}$ laboratory were received from outpatient or PHC clinics, patients attending these facilities comprised a relatively substantial proportion of all cases of thrombocytopenia.

Although the study is somewhat compromised by a paucity of clinical information, the critical role of laboratory testing allowed for determination of the cause of the low platelet count in $62 \%$ of the patients based on a review of laboratory records, as well as for evaluation of the adequacy of the laboratory work-up. Since CHBAH is a haematology referral centre, chemotherapy effect and primary haematological causes of thrombocytopenia (such as aplastic anaemia and malignant marrow infiltration) were prominent in this cohort, collectively comprising some $40 \%$ of the low platelet counts seen. Although malaria and TTP are often emphasised as 
Table 3. Analysis of adequacy of laboratory work-up

\begin{tabular}{|c|c|c|c|c|}
\hline & $\begin{array}{l}\text { Completely } \\
\text { inadequate work-up } \\
\text { frequency } \\
n / N(\%) ; p \text {-value }{ }^{*}\end{array}$ & $\begin{array}{l}\text { Adequate work-up } \\
\text { frequency } \\
n / N(\%) ; p \text {-value }\end{array}$ & $\begin{array}{l}\text { Frequency of coagulation } \\
\text { testing omission among } \\
\text { patients with an incomplete } \\
\text { work-up } \\
n / N(\%) ; p \text {-value }\end{array}$ & $\begin{array}{l}\text { Frequency of peripheral } \\
\text { smear review omission } \\
\text { among patients with an } \\
\text { incomplete work-up } \\
n / N(\%) ; p \text {-value }\end{array}$ \\
\hline All patients & $\begin{array}{l}42 / 366(11.5) \\
\text { N/A }\end{array}$ & $\begin{array}{l}\text { 181/366 (49.5); } \\
\text { N/A }\end{array}$ & $\begin{array}{l}\text { 118/185 (63.8); } \\
\text { N/A }\end{array}$ & $\begin{array}{l}70 / 185(37.8) \\
\text { N/A }\end{array}$ \\
\hline Medical & $\begin{array}{l}9 / 107(8.4) \\
0.16\end{array}$ & $\begin{array}{l}41 / 107(38.3) \\
\mathbf{0 . 0 0 4}\end{array}$ & $\begin{array}{l}40 / 65(61.5) \\
0.38\end{array}$ & $\begin{array}{l}14 / 65(21.5) \\
0.0005\end{array}$ \\
\hline Surgical & $\begin{array}{l}6 / 23(26.1) \\
0.036\end{array}$ & $\begin{array}{l}8 / 23(34.8) \\
0.11\end{array}$ & $\begin{array}{l}2 / 15(13.3) \\
<0.0001\end{array}$ & $\begin{array}{l}7 / 15(46.7) \\
0.32\end{array}$ \\
\hline Obstetrics/gynaecology & $\begin{array}{l}2 / 19(10.5) \\
0.62\end{array}$ & $\begin{array}{l}4 / 19(21.0) \\
0.009\end{array}$ & $\begin{array}{l}7 / 15(46.7) \\
0.12\end{array}$ & $\begin{array}{l}4 / 15(26.7) \\
0.26\end{array}$ \\
\hline $\begin{array}{l}\text { Haematology/oncology (adult and } \\
\text { paediatric) }\end{array}$ & $\begin{array}{l}1 / 86(1.2) \\
\mathbf{0 . 0 0 0 1}\end{array}$ & $\begin{array}{l}74 / 86(86.0) \\
<0.0001\end{array}$ & $\begin{array}{l}8 / 12(33.3) \\
0.027\end{array}$ & $\begin{array}{l}0 / 12(0.0) \\
\mathbf{0 . 0 2 6}\end{array}$ \\
\hline Paediatrics $^{\dagger}$ & $\begin{array}{l}0 / 13(0.0) \\
0.2\end{array}$ & $\begin{array}{l}8 / 13(61.5) \\
0.27\end{array}$ & $\begin{array}{l}4 / 5(80.0) \\
0.4\end{array}$ & $\begin{array}{l}1 / 5(20.0) \\
0.37\end{array}$ \\
\hline Neonatal wards & $\begin{array}{l}0 / 23(0.0) \\
\mathbf{0 . 0 5 5}\end{array}$ & $\begin{array}{l}23 / 23(100.0) \\
<0.0001\end{array}$ & N/A & N/A \\
\hline $\mathrm{ICU}^{\ddagger}$ & $\begin{array}{l}1 / 37(2.7) ; \\
0.055\end{array}$ & $\begin{array}{l}\text { 12/37 (32.4); } \\
\mathbf{0 . 0 2}\end{array}$ & $\begin{array}{l}\text { 10/25 (40.0); } \\
\mathbf{0 . 0 0 8}\end{array}$ & $\begin{array}{l}14 / 25(56.0) ; \\
0.26\end{array}$ \\
\hline Miscellaneous outpatient clinics & $\begin{array}{l}5 / 16(31.3) \\
\mathbf{0 . 0 2 6}\end{array}$ & $\begin{array}{l}6 / 16(37.5) \\
0.24\end{array}$ & $\begin{array}{l}8 / 10(80.0) \\
0.23\end{array}$ & $\begin{array}{l}5 / 10(50.0) \\
0.31\end{array}$ \\
\hline PHC clinics & $\begin{array}{l}11 / 12(91.7) \\
<\mathbf{0 . 0 0 0 1}\end{array}$ & $\begin{array}{l}1 / 12(8.3) \\
0.003\end{array}$ & $\begin{array}{l}5 / 11(45.6) \\
0.16\end{array}$ & $\begin{array}{l}11 / 11(100.0) \\
<\mathbf{0 . 0 0 0 1}\end{array}$ \\
\hline
\end{tabular}

causes of thrombocytopenia, they proved comparatively rare, each accounting for $<5 \%$ of the thrombocytopenic samples. Among the HIV-positive patients, common causes of thrombocytopenia included chemotherapy for high-grade lymphomas, BMTB and sepsis. Interestingly, although both ITP and TTP are well-described causes of HIV-associated thrombocytopenia, the prevalence rates of these diseases did not differ between HIV-positive and negative patients in this cohort, possibly in part because of small sample sizes.

HIV status was documented in approximately $70 \%$ of the patients, of whom just under half were HIV-positive. This is not surprising given the high background prevalence of HIV in the SA population, as well as the strong association between HIV infection and thrombocytopenia. In contrast, hepatitis $\mathrm{B}$ and $\mathrm{C}$ positivity were uncommon, and presented most frequently in patients with thrombocytopenia attributable to chronic liver disease. However, as most patients were not tested for hepatitis $\mathrm{B}$ and $\mathrm{C}$, their roles in the pathogenesis of thrombocytopenia in this setting remain unclear. Nonetheless, we noted with interest that none of the patients with aplastic anaemia had viral hepatitis, and only one patient with ITP tested seropositive for hepatitis C.

Among the hospitalised patients, laboratory work-up was judged to be good in the majority of paediatric and ICU patients as well as in neonates and haematology/oncology patients. In contrast, workup was generally suboptimal in patients seen in outpatient clinics or admitted to surgical wards, and was very poor in patients seen at PHC clinics. While it is possible that some of the latter patients might have been transferred to an alternative hospital for work-up, this finding could reflect a deficiency in the clinical approach to thrombocytopenia among healthcare workers at primary facilities. Further studies in this regard would be of interest. Of concern is that among the common reasons for the work-up being judged incomplete was the absence of peripheral blood smear review, which was omitted in $\sim 20 \%$ of patients. As it is a laboratory policy to review a blood film in samples with a platelet count $<100 \times 10^{9} / \mathrm{L}$, this finding highlights deficiencies in both the clinical and laboratory services, possibly as a result of the pressures of high case volumes and a skills shortage in both these settings. Also of note was that investigation for coagulopathy was poor, being requested in just over $40 \%$ of all patients. This is of particular concern in view of the fact that DIC is an important cause for thrombocytopenia in patients with sepsis, the prevalence of which was high in our cohort. DIC is associated with a high mortality rate and may necessitate fresh-frozen plasma and/or cryoprecipitate infusion. It is therefore important that a coagulopathy screen (including an INR, PTT, fibrinogen level and D-dimer assay) be performed in all patients with thrombocytopenia in the presence of any of its possible precipitants, including sepsis. ${ }^{[5,6]}$ Not unexpectedly, we found an independent association between the presence of laboratory evidence of a coagulopathy and the presence of both chronic liver disease and sepsis. Of interest was that an association was also evident in patients with BMTB, suggesting that a consumptive coagulopathy (such as DIC) is a likely contributor to the low platelet count frequently seen in these patients. This is supported by the normal megakaryocyte numbers 
as well as the raised immature platelet fraction (a parameter that reflects increased platelet production) seen in many patients with BMTB. ${ }^{[7]}$

\section{Conclusion}

Thrombocytopenia was found to be common in hospitalised patients in the academic state sector in Johannesburg, but relatively rare in the outpatient setting. Chemotherapy and sepsis were identified as the commonest causes, irrespective of HIV status. The quality of laboratory work-up was found to be poorest in the PHC clinic sector, and varied between disciplines within the hospital setting. The findings emphasise the need for a standardised approach to thrombocytopenia investigation and increased awareness on the part of clinicians, most particularly among PHC providers and those working in surgical disciplines.

\section{References}

1. Stasi R. How to approach thrombocytopenia. Hematology Am Soc Hematol Educ Program 2012;2012:191-197. [http://dx.doi.org/10.1182/asheducation-2012.1.191]

. Sekhon SS, Roy V. Thrombocytopenia in adults: A practical approach to evaluation and management. South Med J 2006;99(5):491-498; quiz 499-500, 533. [[http://dx.doi.org/10.4021/jh28w]

3. Schwartz G, Kessler SW, Rothwell SW, et al. Inhibitory effects of HIV-1-infected stromal cell layers on the production of myeloid progenitor cells in human long-term bone marrow cultures. Exp Hematol 1994;22(13):1288-1296.

4. Sakaguchi M, Sato T, Groopman JE. Human immunodeficiency virus infection of megakaryocytic cells. Blood 1991;77(3):481-485.

5. Hunt BJ. Bleeding and coagulopathies in critical care. N Engl J Med 2014;370(9):847-859. [http:// dx.doi.org/10.1056/NEJMra1208626]

6. Levi M. Current understanding of disseminated intravascular coagulation. $\mathrm{Br} \mathrm{J}$ Haematol 6. Levi M. Current understanding of disseminated intravascular coagul
2004;124(5):567-576. [[http://dx.doi.org/10.1046/j.1365-2141.2003.04790.x].

7. Vaughan J, Wiggill T, Munster M. Immature platelet fraction levels in a variety of bone marrow Vaughan J, Wiggill T, Munster M. Immature platelet fraction levels in a variety of bone marrow
pathologies in South African HIV-positive patients with thrombocytopenia. Hematology 2014;19(7):417-423. [http://dx.doi.org/10.1179/1607845413Y.0000000143]

Accepted 13 October 2014. 